\title{
INFLUENCE OF LASER SURFACE TREATMENT ON THE TENSILE SHEAR STRENGTH OF RESISTANCE WELDED CFRTP
}

\author{
KAZUTO TANAKA, MASATOSHI OKAMOTO, YUSUKE NAKANO \& TSUTAO KATAYAMA \\ Department of Biomedical Engineering, Doshisha University, Japan
}

\begin{abstract}
In the automotive industry, Carbon Fiber Reinforced Thermoplastics (CFRTP), which have advantages in terms of high toughness, high productivity and high recycling efficiency, are expected to be used for automotive parts. Although the composite materials allow the integral molding of complicated structure, assembly of the vehicle still needs a lot of joints such as bolts and rivets. These fastening methods cause the increase of weight and require holes that cause stress concentration. In the aircraft industry, the technique for welding of CFRTP by direct resistance heating to metal mesh has been applied. Although this fastening method needs no holes, there is a problem of delamination between the metal mesh and matrix. Meanwhile, the direct resistance welding has been developed, in which carbon fibers are used for heating elements. However, further improvement of strength and reduction of the bonding area to allow light weight structures are required. One of the methods enhancing the bonding strength is surface treatment of CFRTP. Laser ablation is an environmentally friendly process of surface treatment that is high in productivity. In this study, in order to evaluate the influence of laser ablation on tensile shear strength, laser ablation was applied to the surface of CFRTP under different conditions. The shear strength was the highest under the conditions of laser scanning in the fiber direction with lower laser power.

Keywords: CFRTP, resistance welding, direct resistance heating, laser surface treatment, tensile shear test, bonding strength, polyamide 6, single fiber pull-out test, interfacial strength.
\end{abstract}

\section{INTRODUCTION}

In the automotive industry, Carbon Fiber Reinforced Plastics (CFRP), which have advantages in terms of high toughness, high productivity and high recycling efficiency, are expected to be used for automotive parts [1], [2]. Although the composite materials allow the integral molding of complicated structure, assembly of the vehicle still needs a lot of joints such as bolts and rivets. As these fastening methods cause the increase of weight and require holes that cause stress concentration, the fastening method for CFRP without holes is expected to be developed [3], [4]. With Carbon Fiber Reinforced Thermoplastics (CFRTP) use thermoplastic resin for the matrix, it is possible to use the welding technology. In the aircraft industry, the technique for welding of CFRTP by direct resistance heating to metal mesh has been applied [5], [6]. Although this fastening method needs no holes, there is a problem of delamination between the metal mesh and matrix. On the other hand, the direct resistance welding has been developed, in which carbon fibers are used for heating elements [7]. However, further improvement of strength and reducing the bonding area to allow light weight structures are required. One of the methods enhancing the bonding strength is surface treatment of CFRTP [8]-[10]. Laser ablation is an environmentally friendly process of surface treatment that is high in productivity [11]. In this study, in order to evaluate the influence of the laser ablation on tensile shear strength, laser ablation was applied to the surface of CFRTP under different conditions and tensile shear tests were conducted. Single fiber pull-out tests were also conducted to evaluate the influence of the laser ablation to the carbon fiber surface on the fiber/matrix interfacial strength. 


\section{MATERIALS AND EXPERIMENTAL PROCEDURES}

\subsection{Materials}

PAN-based carbon fibers were used as the resistance heating element. Polyamide 6 (Prototype, PA 6, Ube Industries, Ltd., Japan), which is processed into non-woven fabric by the melt blown method (Kuraray Co., Ltd., Japan) with weight per unit area at $50 \mathrm{~g} / \mathrm{m}^{2}$, was used for the matrix in welding area. Specimens were molded by the high-speed compression molding method [12]. Non-crimp stitched carbon fabrics (NCF, $300 \mathrm{~g} / \mathrm{m}^{2},\left[0^{\circ} / 90\right]$, Toho Tenax, Japan), that were PAN-based carbon fibers stitched together by polyester sewing thread, were used for the reinforced fabrics. Specimen dimensions were $25 \mathrm{~mm} \times 100 \mathrm{~mm} \times$ $2 \mathrm{~mm}$.

\subsection{Laser surface treatment for CFRTP and single fiber pull out test}

Laser surface treatments were conducted with a dioxide carbon laser cutting machine (Laser Pro SPIRIT SI-30, COMNET, Japan) in which the maximum laser power supply was $30 \mathrm{~W}$ and the maximum feeding rate was $1.524 \mathrm{~m} / \mathrm{s}$. Table 1 shows the conditions of laser treatment for each specimen. "\%" means a percentage to the maximum laser power of $30 \mathrm{~W}$. Fig. 1 shows the laser scanning directions for the specimens. Laser treatment was performed at the bonding area $(12.5 \mathrm{~mm} \times 25 \mathrm{~mm})$ of the CFRTP specimens.

Carbon fiber surface for $\mathrm{CF} 0$ and $\mathrm{CF} 2$ were analyzed with Laser Raman spectrophotometer (NRS-2000, JASCO, Japan). The band intensity ratio (ID/IG) was calculated by using areas of the D band (Diamond structure ID) and the G band (Graphite structure, IG) which were obtained by curve-fitting the results of spectral peaks separation.

Fig. 2 shows the schematic drawing of the experimental setup for single fiber pull-out test. After a single carbon fiber, which was laser-treated under the conditions of CF0, CF1 and CF2 in the fiber direction was glued to a polyester tab, it was attached to a micromanipulator. PA6 resin was placed on the aluminum plate heated to $250^{\circ} \mathrm{C}$. After the single fiber was embedded into the melted PA6 resin by operating the micromanipulator, it was air-cooled. After chucking the polyester tab of a pull-out specimen, the supporting part of the tab was cut and a pull-out test was performed with a constant displacement rate of $1.67 \times 10^{-6} \mathrm{~m} / \mathrm{s}$ using a testing machine for micro material (MMT-11 N, Shimadzu Co., Japan, Load capacity: $10 \mathrm{~N}$ ). The precise embedded fiber length 1 and fiber diameter $\mathrm{d}$ were measured with the Scanning Electron Microscope (SEM, JSM-6390, JEOL, Japan) after the pull-out tests. The fiber/matrix interfacial shear strength, $\tau$, was calculated by the following eqn (1):

$$
\tau=\frac{F_{\max }}{\pi d l},
$$

where:

- $\tau=$ fiber/matrix interfacial shear strength.

- $\mathrm{F}_{\max }=$ maximum tensile load.

- $\mathrm{d}=$ fiber diameter.

- $1=$ fiber embedded length in the resin

\subsection{Resistance welding and tensile shear test}

Fig. 3 shows the schematic drawing of the experimental setup for resistance welding. Fig. 4 shows the lamination of the specimens at the welding part. Current with the input power of $0.1 \mathrm{~kW}$ was applied to the carbon fibers by a power supply unit (T162-6014AAH, Thamway, 
Japan) and an impedance converter (T010-6012, Thamway, Japan). After melting the PA6 resin, pressure of $0.1 \mathrm{MPa}$ was applied to the welding area for $60 \mathrm{~s}$ by a universal testing machine (Autograph AG-100kN, Shimadzu Corporation, Japan).

Table 1: Laser treatment of specimen.

\begin{tabular}{ccc}
\hline Specimen & Head speed $[\mathrm{m} / \mathrm{s}]$ & Power[W] \\
\hline CF0 & 0 & 0 \\
\hline CF1 & & $1.5(5 \%)$ \\
\hline CF2 & & $3.0(10 \%)$ \\
\hline CF3 & & $6.0(20 \%)$ \\
\hline CF4 & & $9.0(30 \%)$ \\
\hline CF5 & $0.76(50 \%)$ & $12(40 \%)$ \\
\hline CF6 & & $15(50 \%)$ \\
\hline CF7 & & $18(60 \%)$ \\
\hline CF8 & & $21(70 \%)$ \\
\hline
\end{tabular}
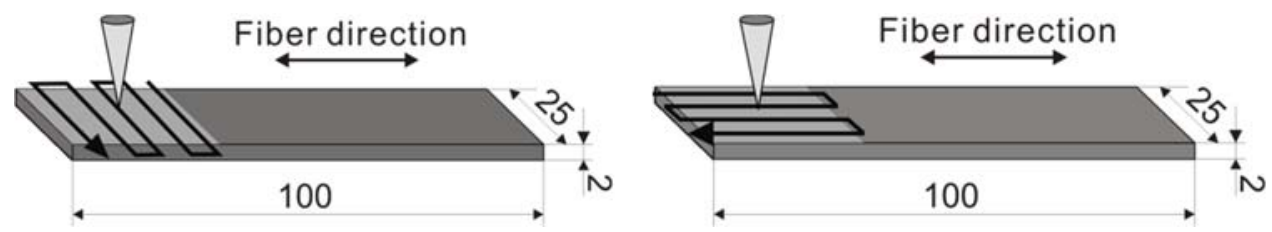

(a) Laser irradiation (scanned in perpendicular direction) (b) Laser irradiation (scanned in fiber direction)

Figure 1: Laser scanning direction for specimen.

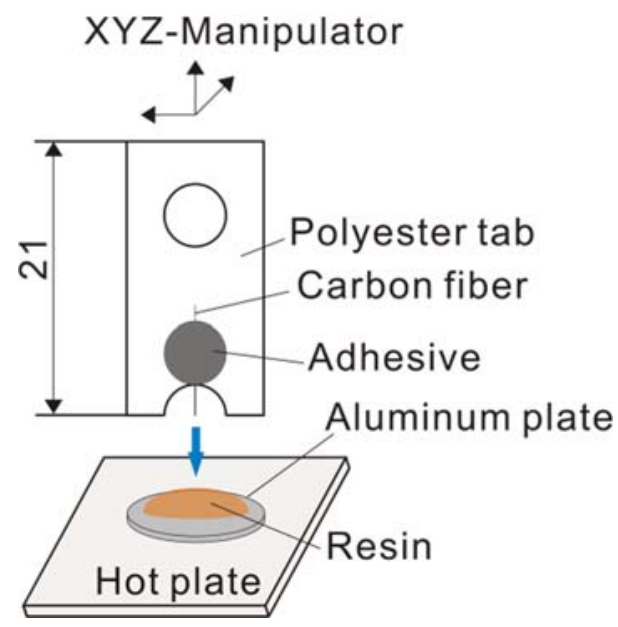

Figure 2: Preparation of single fiber pull out specimen. 


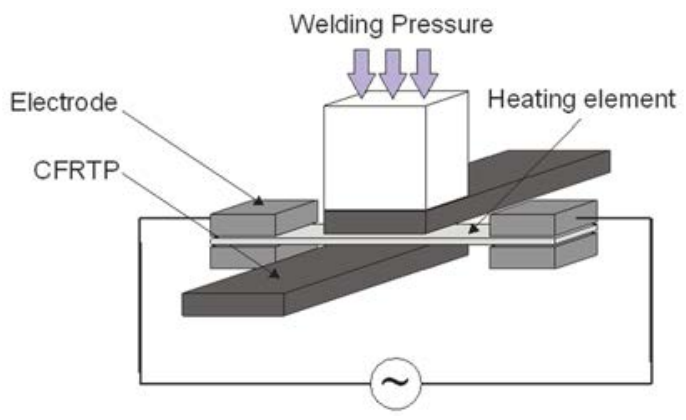

Figure 3: Schematic drawing of experimental setup for direct resistance welding.

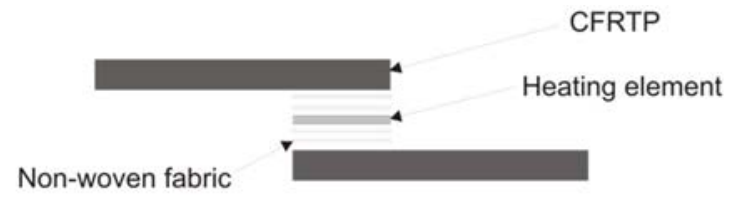

Figure 4: Schematic drawing of lamination for direct resistance welding.

Tensile shear tests were conducted based on JIS-K6850 with the universal testing machine. The laser treated surfaces and the fracture surfaces of the specimens were observed with SEM and a 3CCD real color confocal microscope (OPTELICS H1200, Lasertec, Japan).

\section{RESULTS AND DISCUSSION}

\subsection{Laser surface treatment of CFRTP}

Fig. 5 shows the band intensity ratios obtained by Raman spectral analysis of CF0 and CF2 fiber surfaces. The ratio of diamond structure of CF2 was higher than that of untreated surfaces. It means that lase treatment changed fiber surface in its structure.

Fig. 6 shows the CF/PA6 interfacial shear strengths obtained by the single fiber pull-out tests. The laser-treated specimen under the condition of CF2 showed smaller fiber matrix interfacial shear strength than that of untreated specimen (CF0), while there was no different between the fiber specimen laser-treated under the condition of CF1 and the untreated specimen. In addition, it is reported that carboxyl groups and hydroxyl groups are produced on the edge face of graphite surface within oxidized carbon fiber, and hydrogen bonds are formed between polyamide and carboxyl groups [13], [14]. The fiber matrix interfacial shear strength of CF2 was decreased by the low ratio of graphite structure, resulting in weaker chemical bonding between the matrix and carbon fiber.

Fig. 7 shows laser-treated surfaces scanned in the perpendicular direction. When the laser power was high, not only the ablation of matrix resin but also the damage of reinforced fiber occurred and the diameter of the reinforced fibers became small in some places.

Fig. 8 shows laser-treated surfaces scanned in the fiber direction. While carbon fibers broke under the relatively high-power conditions of CF6 (15W, 50\%) and CF8 (21W, 70\%), the resin on the specimen surface was eliminated under the condition of CF2 (3W, 10\%). 
Fig. 9 shows surface roughness of laser-treated specimens which were measured by the 3CCD real color confocal microscope. Roughness of specimens which were laser-treated in the fiber direction was larger than that of specimens in the perpendicular direction. Fig. 10 shows surface areas of specimens which were irradiated by a laser $(3 \mathrm{~W}, 10 \%)$ in each

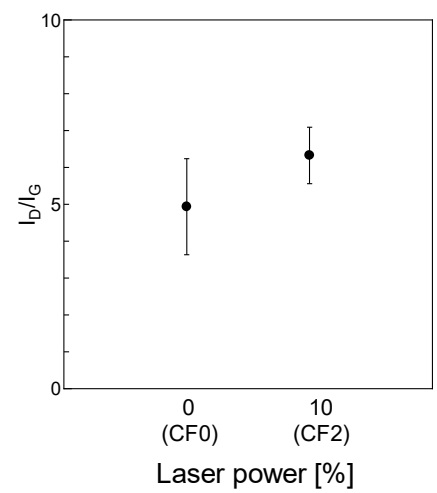

Figure 5: Raman spectral analysis of the fiber surface of CF0 and CF2.

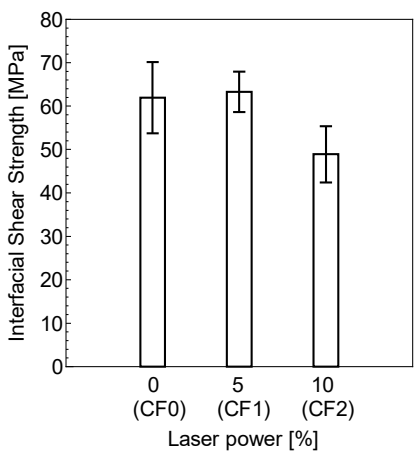

Figure 6: $\mathrm{CF} / \mathrm{PA} 6$ interfacial shear strength of $\mathrm{CF} 0, \mathrm{CF} 1$ and $\mathrm{CF} 2$.

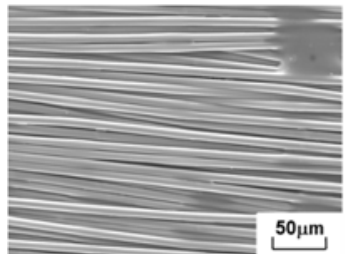

(a) CF2(power $10 \%$ )

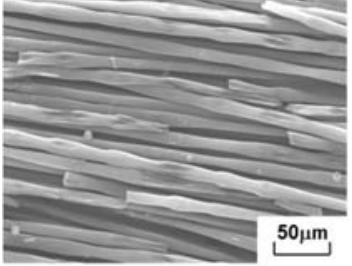

(c)CF6(power 50\%)

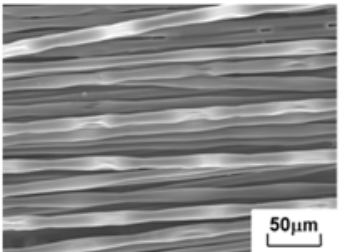

(b) $\mathrm{CF} 4($ power $30 \%$ )

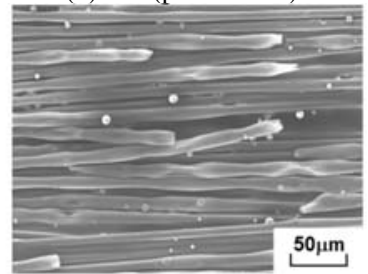

(d)CF8(power $70 \%)$

Figure 7: Laser treated surface scanned in the perpendicular direction (head speed $50 \%$ ). 


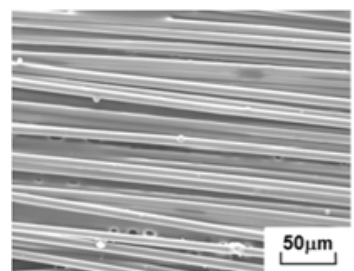

(a) CF2(power 10\%)

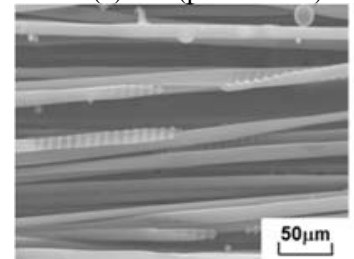

(c)CF6(power 50\%)

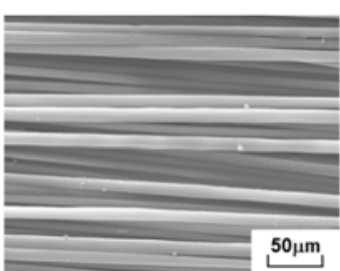

(b) CF4(power 30\%)

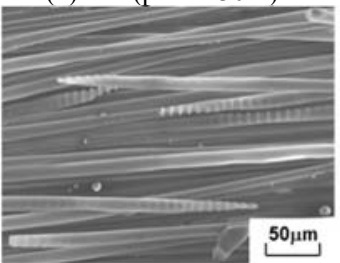

(d)CF8(power 70\%)

Figure 8: Laser treated surface scanned in the fiber direction (head speed 50\%).

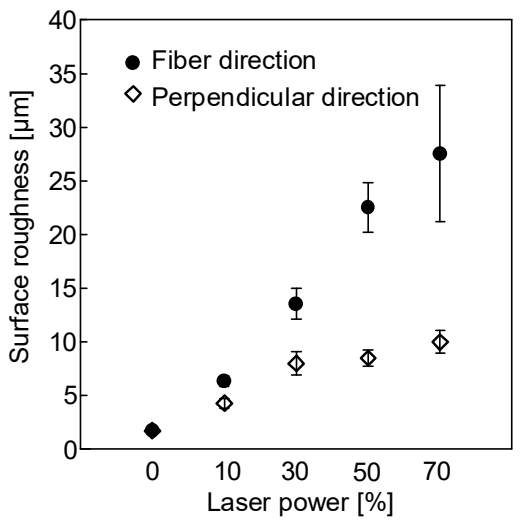

Figure 9: Surface roughness of specimen.

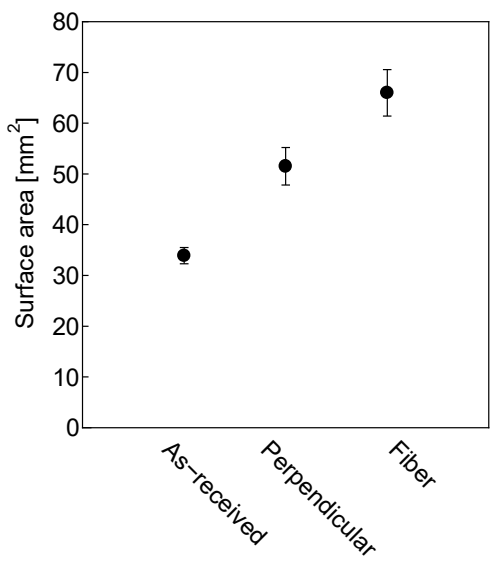

Figure 10: Surface area of specimen. 
scanning direction and as received specimen. The surface area of the specimen which was irradiated in the fiber direction was the largest.

From the above, laser irradiation scanned in the fiber direction is considered to be the appropriate treatment, in which only matrix resin can be removed without damaging the reinforced fibers.

\subsection{Tensile shear strength}

Fig. 11 shows the tensile shear strengths of the resistance welded CFRTP which were scanned in the perpendicular direction for laser irradiation. The highest tensile shear strength of 19.0 $\mathrm{MPa}$ was obtained under the condition of CF2 (3W, 10\%).

Fig. 12 shows the tensile shear strengths of the resistance welded CFRTP which were scanned in the fiber direction for laser irradiation. The highest tensile shear strength of 20.9 $\mathrm{MPa}$ was obtained under the condition of CF2 (3W, 10\%). Fig. 13 shows the fracture surfaces for tensile shear tests. While the fibers of the $90^{\circ}$ direction, which are the carbon fibers for heating element, are exposed on the fracture surface of CF2 $(3 \mathrm{~W}, 10 \%)$, the reinforced fibers of $0^{\circ}$ direction, which are the surface of welded CFRTP, are exposed on the fracture surface of CF4, CF6 and CF8. Fig. 14 shows the schematic drawing of fracture types of tensile shear tests. For CF2, the fracture occurred in the welded layer as shown in Fig. 14(a). For the other conditions with higher laser power, the fracture occurred at interface between welded layer and welded CFRTP as shown in Fig. 14(b). It means that bonding strength between welded layer and welded CFRTP of CF2 $(3 \mathrm{~W}, 10 \%)$ was higher than that of specimens under the conditions of higher laser power.

The shear strength was the highest under the conditions of CF2 $(3 \mathrm{~W}, 10 \%)$ with the laser scanning in the fiber direction. Laser scanning in the fiber direction with lower laser power, which reduces the damage of the reinforcing fibers and can remove only the matrix resin, has highest shear strength due to increase of the surface area.

\section{CONCLUSION}

In order to evaluate the influence of the laser ablation on tensile shear strength, laser ablation was applied to the surface of CFRTP under different conditions. Laser scanning in the fiber direction with lower laser power, which reduces the damage of the reinforcing fiber and can remove only the matrix resin and increase the surface area. Therefore, the highest tensile share strength of $20.9 \mathrm{MPa}$, was obtained under the condition of CF2 (3w, 10\%, in fiber direction).

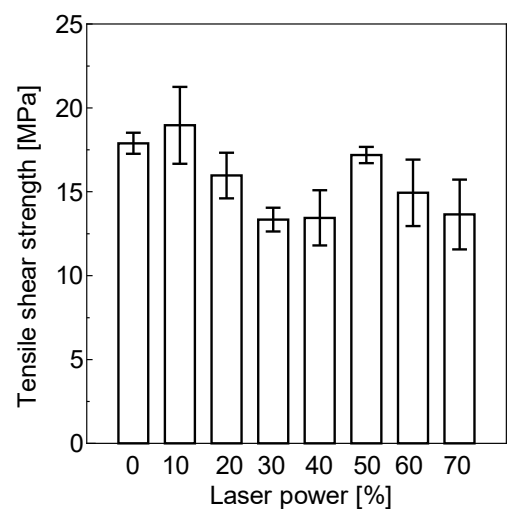

Figure 11: Tensile shear strength (perpendicular direction). 


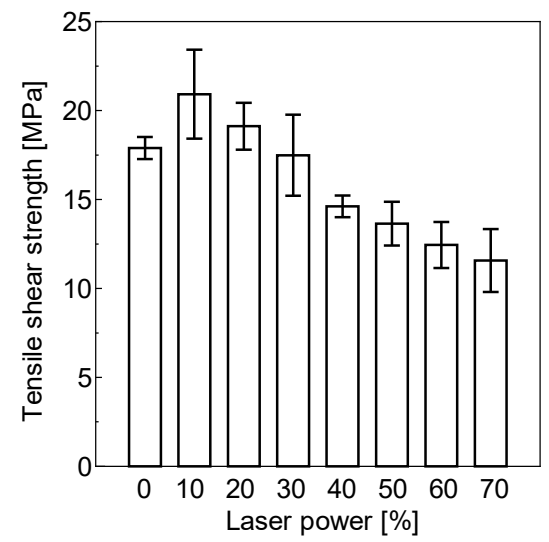

Figure 12: Tensile shear strength (fiber direction).

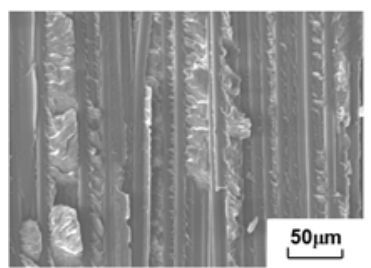

(a) $\mathrm{CF} 2($ power $10 \%$ )

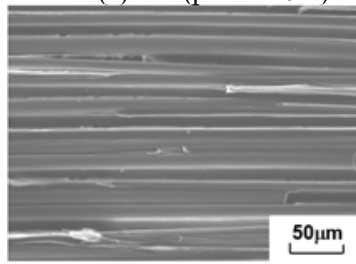

(c)CF6(power 50\%)

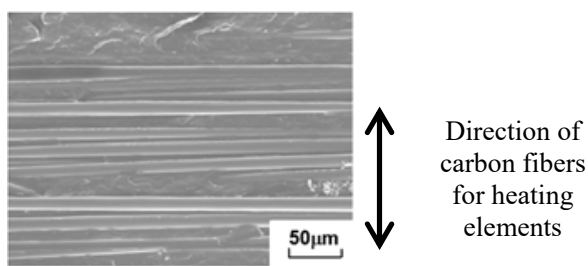

(b) $\mathrm{CF} 4($ power $30 \%$ )

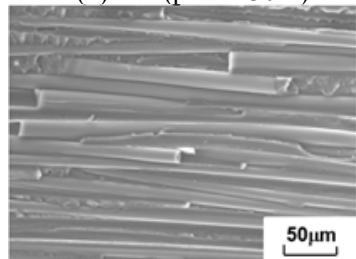

(d)CF8(power 70\%)

Figure 13: Fracture surfaces for tensile shear tests (fiber direction, head speed 50\%).

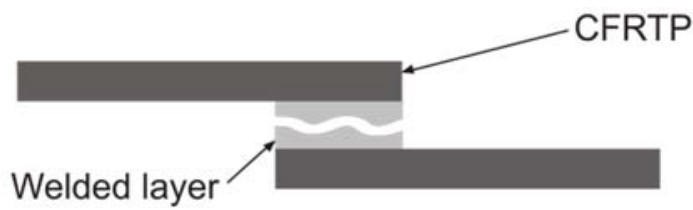

(a) Interlaminar fracture

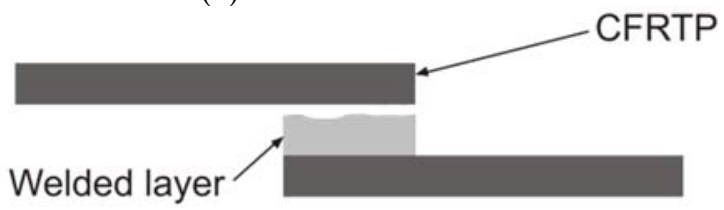

(b) Interfacial fracture

Figure 14: Fracture types of tensile shear test. 


\section{REFERENCES}

[1] Wadahara, E. \& Kitano, A., Automotive Lightweight Structural Elements of Carbon Fiber Reinforced Plastics. The Society of Materials Science Japan ,64(9), pp.295-301, 2008.

[2] Composites penetration growth in Automotive: towards mass production 2010-2020 trends and forecasts. JEC Composites, pp. 13-22, 2011.

[3] Amancio-Filho, S.T. \& Santos, J.F.D., Joining of Polymers and Polymer-Metal Hybrid. Polymer Engineering and Science, 49, pp. 1461-1476, 2009.

[4] Xiao, Y. \& Ishikawa, T., Bearing strength and failure behavior of bolted composite joints. Composites Science and Technology, 65, pp. 1022-1031, 2005.

[5] Dube, M., Hubert, P., Gallet, J.N.A.H., Stavrov, D., Bersee, H.E.N. \& Yousefpour, A., Fatigue performance characterization of resistance welded thermoplastic composites. Composites Science and Technology, 68, pp. 1759-1765, 2008.

[6] Hou, M., Yang, M., Beehag, A., Mai, Y. \& Ye, L., Resistance welding of carbon fibre reinforced thermoplastic composite using alternative heating element. Composite Structures, 47, pp. 667-672, 1999.

[7] Nakano, Y., Tanaka, K., Katayama, T. \& Shinahara, M., Resistance Welding of CFRTP by Using Direct Resistance Heating to Carbon Fiber. Proceedings of the 5th Symposium on Composite Materials for Automotive Applications, pp. 59-60, 2013.

[8] Benard, Q., Fois, M. \& Grisel, M., Peel ply surface treatment for composite assemblies: Chemistry and morphology effects. Composites Part A, 36, pp. 1562-1568, 2005.

[9] Kim, J.K. \& Lee, D.G., Characteristics of plasma surface treated composite adhesive joints at high environmental temperature. Composite Structures, 57. pp. 37-46, 2002.

[10] Harris, A.F. \& Beevers, A., The effects of grit-blasting on surface properties for adhesion. Adhesion \& Adhesives, 19, pp. 445-452, 1999.

[11] Nishio, K., Yamaguchi, T., Era, H. \& Kotoh, M., Surface Modification of Titanium Using Laser Beam. Japan Institute of Metal and Materials, 69, pp. 509-516, 2005.

[12] Tanaka, K., Kobashi, N., Kinoshita, Y., Katayama, T. \& Uno, K., Compression Molding of Carbon Fiber Reinforced Thermoplastic Using Non-Woven Stitched Multi-Axial Cloth Means of Induction Heating System. The Society of Materials Science Japan, 58(7), pp. 642-648, 2009.

[13] Weinberg, N.L. \& Reddy, T.B., Electrochemical oxidation of the surface of graphite fibers. Journal of Applied Electrochemistry, 3, pp. 73-75, 1973.

[14] Sesha Sainath, A.V., Inoue, T., Yonetake, K. \& Koyama, K., Thermal behavior of poly (acryloyloxybenzonic acid)/nylon 6 blends. Polymer, 42, pp. 9859-9862, 2001. 